\title{
Neumonía adquirida en la comunidad en niños: Aplicabilidad de las guías clínicas.
}

\author{
ANA MARÍA ÁLVAREZ P*.
}

\section{Guidelines for community acquired pneumonia in children and its aplicability}

Community acquired pneumonia (CAP) is one of main causes of morbidity and mortality in childhood. In spite of its definition varies largely, the most accepted to recommend treatments is the presence of fever and/or acute respiratory symptoms plus parenchyma infiltrates in chest radiography. Pneumonia is associated to various risk factors and is more frequent under 5 years old. Etiological diagnosis is influenced by age and can be yielded in 40 to 80 percent of cases. There are several clinical guidelines for its management, we analyze some aspects of these guidelines as etiology, diagnosis and treatment.

Key words: Pneumonia; Community; Treatment; Guidelines

La neumonía adquirida en la comunidad (NAC) es una de las más frecuentes y serias enfermedades infecciosas de la infancia con cifras de morbimortalidad elevadas. Se estima una incidencia anual en E.U.A. y Europa de aproximadamente 35 a 45 casos por 1.000 niños bajo 5 años de edad, siendo los antecedentes de prematurez, desnutrición, nivel socioeconómico bajo, exposición a contaminantes inhalados y asistencia a jardines infantiles, los factores de riesgo más importantes ${ }^{1-2}$. En Chile, NAC constituye la segunda causa de de hospitalización y es responsable de 47 a $52 \%$ de los egresos hospitalarios en niños bajo 2 años de edad. La tasa de mortalidad nacional varía entre 0,5 y 4 por $1.000 / R N$ vi$\operatorname{vos}^{3}$.

La elevada mortalidad asociada a las infecciones respiratorias, esencialmente en países subdesarrollados, y la dificultad en el diagnóstico etiológico, han motivado publicaciones de guías de práctica clínica basadas en evidencia científica para el manejo de la NAC en niños, en las que el nivel de evidencia principalmente está sustentado por opinión de expertos, trabajos prospectivos o series de gran número de casos, y pocos en trabajos randomizados, doble ciego o estudios bien diseñados de caso-control. En Chile, en 1999 se publicó el Consenso de Especialistas en Enfermedades Respiratorias para el manejo de la $\mathrm{NAC}$ en niños, que no especifica el grado de evidencias de sus indicaciones.
Estas guías son necesariamente extensas y analizan diferentes aspectos de la NAC: epidemiología, etiología, diagnóstico clínico, radiológico, de laboratorio general y microbiológico, criterios de hospitalización, de traslado a UCI, manejo general, antimicrobiano y de sus complicaciones $^{3-6}$.

Se resumen algunos de los aspectos más relevantes de estas guías.

\section{Etiología}

Un gran número de microorganismos pueden causar neumonía en los niños y determinar la causa es muchas veces difícil. Debido a lo invasor que es realizar cultivo directo de tejido pulmonar, la mayoría de los estudios publicados utiliza exámenes de laboratorios que proveen sólo evidencia indirecta de neumonía (hemocultivos, aspirados nasofaríngeos, hemograma, PCR y tests serológicos). En la Tabla 1 se resume el porcentaje de agentes etiológicos encontrados en tres de los estudios más recientemente publicados. La literatura indica que las etiologías específicas son dependientes principalmente de la edad (Tabla 2) y concluyen que: Streptococcus pneumoniae es la bacteria más frecuentemente identificada a cualquier edad y en mucho menor porcentaje, bacterias como Staphylococcus aureus y Haemophilus influenzae, incluyendo cepas no tipificables. Los virus respiratorios son los más frecuentes bajo

"Unidad de Infecciosos, Servicio de Pediatría, Hospital San Juan de Dios.

E-mail: amap@mi.cl 
Tabla 1. Neumonía adquirida en la comunidad en Pediatría - Etiología

\begin{tabular}{lccc}
\hline Lugar de estudio & Etiología conocida & Viral & Bacteriana \\
Ambulatorio $^{7}$ & $43 \%$ & $20 \%$ & $40 \%$ \\
Hospital $^{8}$ & $85 \%$ & $62 \%$ & $53 \%$ \\
Poblacional $^{9}$ & $66 \%$ & $25 \%$ & $51 \%$ \\
\hline
\end{tabular}

Tabla 2. Neumonía adquirida en la comunidad en Pediatría - Etiología según la edad

\begin{tabular}{|c|c|c|c|c|}
\hline & Neonatos & 1-3 meses & 4 a 48 meses & 5 a 15 años \\
\hline Streptococcus agalactiae & +++ & - & - & - \\
\hline Virus respiratorios & - & +++ & +++ & + \\
\hline Streptococcus pneumoniae & - & ++ & ++ & ++ \\
\hline Mycoplasma pneumoniae & - & - & + & +++ \\
\hline Chlamydia pneumoniae & - & - & + & +++ \\
\hline
\end{tabular}

Tabla 3. Parámetros clínicos y epidemiológicos orientadores a diferentes etiologías.

\begin{tabular}{lccc}
\hline & $\begin{array}{c}\text { Neumonía } \\
\text { virus respirat }\end{array}$ & $\begin{array}{c}\text { Neumonía } \\
\text { atípica }\end{array}$ & $\begin{array}{c}\text { Neumonía } \\
\text { típica }\end{array}$ \\
\hline Edad & M. pneumoniae & S. pneumoniae \\
\hline Estación climática & Invierno & Mayor 5 años & Todas \\
Inicio & Variable & Todas (primavera) & Invierno \\
C. estado gral & Variable & Escaso & Brusco \\
Fiebre & Variable & No alta & Variable \\
Taquipnea & Común & Infrecuente & Alta \\
Tos & Seca-paroxística & Seca-paroxística & Productiva \\
Otros síntomas & Varios & Varios & Dolor abdominal \\
Dolor costal & No & No & Sí \\
Examen físico & Variable, sibilancias & Variable (ES) & Estertores crepitantes \\
Leucocitosis & Variable (linfocitosis) & Inhabitual & Leucocitosis (neutrofilia) \\
PCR & Variable & Normal & Alta \\
Radiología & Intersticial & Variable & Consolidación lobar/ \\
Efusión pleural & No & segmentaria \\
Ambiente epidémico & Frecuente & Brotes & Frecuente \\
& & & No \\
\hline
\end{tabular}

los 5 años de edad y de éstos, VRS es el más común bajo 2 años de edad. Mycoplasma pneumoniae adquiere importancia en la edad escolar. La etiología mixta oscila entre 8 y $30 \%{ }^{7-9}$.

\section{Diagnóstico}

La neumonía puede ser definida como un proceso inflamatorio agudo del parénquima pulmonar, que se reconocerá por medio de una radiografía de tórax y que clínicamente puede presentar un amplio espectro de síntomas.

\section{Enfoque diagnóstico inicial}

En 1994 se publicó la primera guía de NAC validada en niños, propuesta por la WHO, la cual basó su diagnóstico en cinco parámetros clínicos: frecuencia respiratoria (más de 50 respira- ciones por minuto en niños bajo un año de edad y más de 40 en niños mayores) retracción del tórax, cianosis, dificultad en alimentarse y ausencia de sibilancias, destinada a países con alta tasa de mortalidad por neumonía especialmente de etiología bacteriana, nivel socioeconómico bajo, difícil acceso a centros hospitalarios y a medicamentos. No obstante, en los países desarrollados está aceptada la conveniencia y utilidad de la confirmación diagnóstica radiológica, con la cual se estimará su extensión, se describirá su patrón radiológico (alveolar o intersticial) y podrán detectarse posibles complicaciones.

Clásicamente se han descrito dos formas clínicas de neumonía: la típica (fiebre, calofríos, puntada de costado y tos productiva) referida principalmente a la etiología neumocóccica y la atípica (comienzo gradual, tos no productiva, 


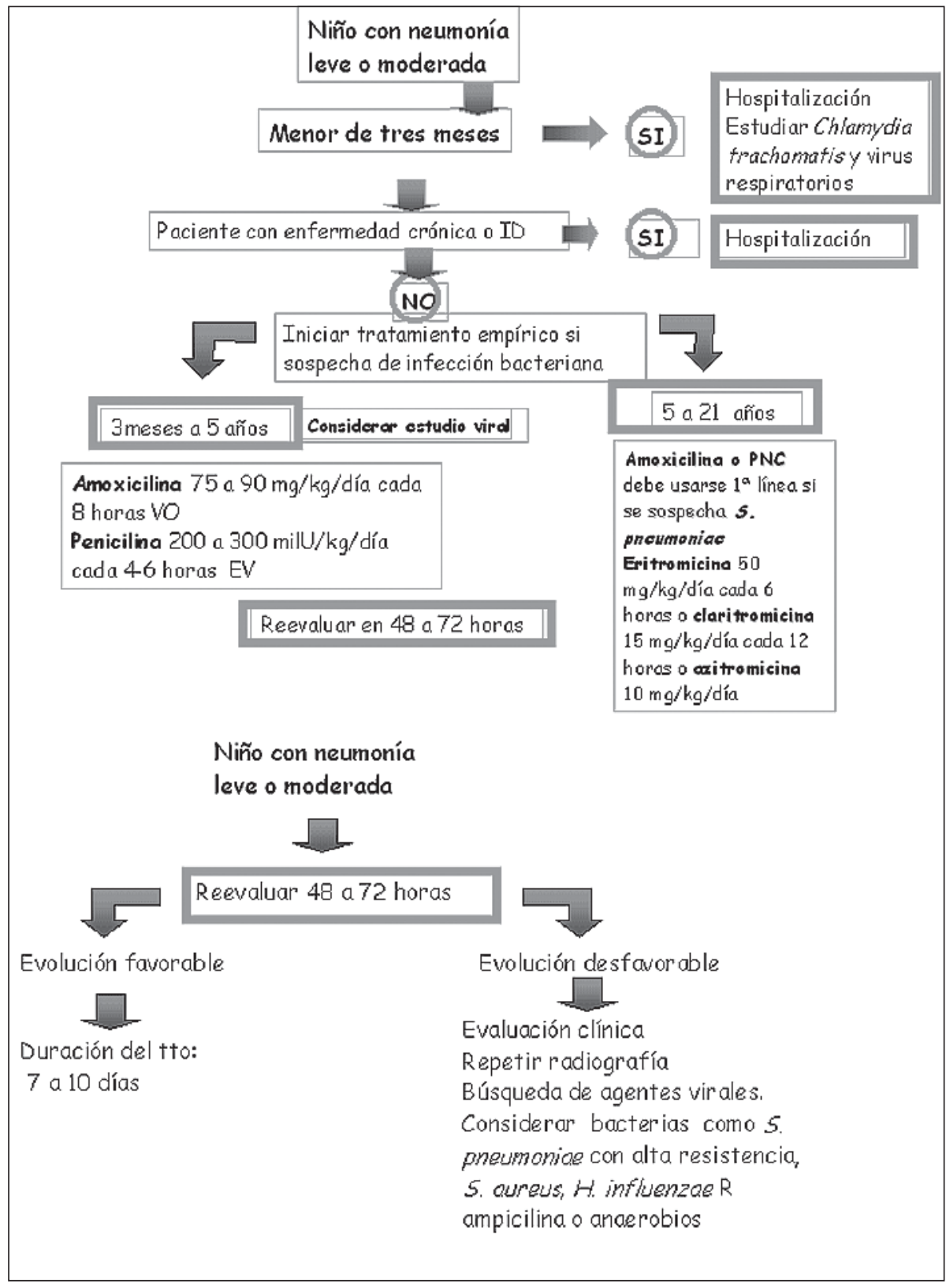

Figura 1. Algoritmo para el tratamiento de neumonías en Pediatría.

cefalea, malestar general, etc) causada preferentemente por virus o bacterias intracelulares. Esta distinción es aplicable a niños mayores y adolescentes, pero en neonatos y lactantes se hace más difícil la diferenciación y en la práctica, estos patrones pueden ser originados por distintos microorganismos.

\section{Radiología y exámenes complementarios}

El patrón radiológico alveolar, atribuible generalmente a neumonía bacteriana, se caracteriza por consolidación lobar, broncograma aéreo y a veces, efusión pleural. El patrón viral presenta hiperinsuflación, infiltrados peribronquiales, atelectasias y adenopatías hiliares. Diversos estudios han intentado correlacionar estos patrones radiológicos y otros exámenes de laboratorios complementarios como la VHS, PCR y el recuento de leucocitos, con etiologías determinadas $^{10-11}$, concluyendo que la etiología bacteriana es más frecuente en pacientes con infiltrados alveolares específicamente lobares en la $\mathrm{Rx}$ de tórax, que los infiltrados intersticiales se ven en neumonías virales y bacterianas y que los exáme- 
nes complementarios no aportan mucho al diagnóstico etiológico, a excepción de la PCR.

\section{Tratamiento}

Debido a la dificultad para diferenciar la etiología de las neumonías, muchas guías recomiendan el uso empírico de antimicrobianos en aquellos pacientes que no es posible vigilar cercanamente, siendo la excepción la neumonía del lactante ingresado con un cuadro clínico claramente vírico. Se recomienda que la decisión del tratamiento se base en algoritmos que comienzan con la edad del niño, la clínica, factores epidemiológicos y finalmente la imagen radiológica (Figura 1).

Teniendo presente que el agente etiológico bacteriano más frecuente desde los 3 meses de edad es $S$. pneumoniae y en conocimiento que su resistencia a penicilina como también a macrólidos en el concierto mundial y específicamente en nuestro país ya alcanzan a sobre $25 \%^{12}$ en penicilina y cerca de $20 \%$ en macrólidos ${ }^{13}$ en infecciones invasoras, sin embargo, es importante saber que el pronóstico del cuadro no tiene relación con el grado de resistencia antimicrobiana. La susceptibilidad a penicilina en infecciones pulmonares debería considerar CIM mayores (resistencia $=$ CIM mayor o igual a $4 \mu \mathrm{g} / \mathrm{ml}$ ) que la aplicada a infecciones meníngeas y óticas (resistencia $=$ CIM mayor o igual a $2 \mu \mathrm{g} / \mathrm{ml})$.Se recomienda que para infecciones por $S$. pneumoniae con CIM no mayor a $2 \mu \mathrm{g} / \mathrm{ml}$, la terapia ideal sea un $\beta$-lactámico y si la CIM es mayor a $1 \mu \mathrm{g} / \mathrm{ml}$, no se recomienda el uso de penicilina oral, cefalosporinas de primera generación ni cefixime $^{14}$.

\section{Resumen}

La neumonía adquirida en la comunidad (NAC) es una de las principales causas de morbimortalidad en la infancia. Si bien su definición varía ampliamente, la más aceptada particularmente respecto a las recomendaciones de tratamiento, es presencia de fiebre y/ o síntomas respiratorios agudos, más evidencia de infiltrados parenquimatosos en la radiografía de tórax. Se asocia a varios factores de riesgo y es más frecuente en menores de 5 años. El diagnóstico etiológico es influenciado por la edad y puede ser precisado en 40 a $80 \%$ de los casos. Existen diversas guías clínicas internacionales para su manejo, se analizan algunos aspectos de estas guías, como etiología, diagnóstico y tratamiento.

\section{Bibliografía}

1.- Dowell S F, Kupronis B A, et al. Mortality from pneumonia in children in USA, 1939-1996. N Engl J Med 2000; 342: 1399-407.

2.- Ruuskanen O, Mertsola J. Childhood communityacquired pneumonia. Semin Respir Infect 1999; 14: 163-72.

3.- Consenso Neumonía adquirida en la comunidad. Rev Chil Enf Respir 1999; 15: 107-9.

4.- Jadavji T Law B Lebel $\mathrm{M}$ et al. A practical guide for the diagnosis and treatment of pediatric pneumonia. Can Med Assoc J 1997; 156 (5): S703-11.

5.- Children's Hosp MC Cincinnati. Guidelines for CAP in children 3m-17a. 2000.

6.- British Thoracic Society. Guidelines for the management of community acquired pnemonia in children. Thorax 2002; 57: suppl I.

7.- Wubbel L, Muniz, Ahmed A, Trujillo M, Carubelli C, Mc Coig C, Abramo T, Leinonen M, Mc Cracken G H $\mathrm{Jr}$. Etiology and treatment of community-acquired pneumonia in ambulatory children. Pediatr Infect Dis J 1999 Feb; 18 (2): 98-104.

8.- Juven T, Mertsola J, Waris M, Leinonen M, Meurman D, Roivainen M, Eskola J, Saikku P, Ruuskanen O. Etiology of community-acquired pneumonia in 254 hospitalized children. Pediatr Infect Dis J 2000 Apr; 19 (4): 293-8.

9.- Heiskanen - Kosma T, Korppi M, Jokinen C, Kurki S, Heiskanen L, Juvonen H, Kallinen S, Sten M, Tarkiainen A, Ronnberg P R, Kleemola M, Makela $\mathrm{PH}$, Leinonen M. Etiology of childhood pneumonia serologic results of a prospective population-based study. Pediatr Infect Dis J, 1998; 17: 986-91.

10.- Korppi M, Krogger L. Comparison of radiological findings and microbial aetiology of children pneumonia. Acta Pediatr 1993; 82 (4): 360-3.

11.- Virkki R, Juven T, Rikalainen H, Svedstrom E, Mertsola J, Ruuskanen O. Differentiation of bacterial and viral pneumonia in children. Thorax 2002; 57: 438-41.

12.- Lagos R et al. Epidemiología de las enfermedades invasoras causadas por Streptococcus pneumoniae en niños chilenos. Rev Chil Infect 2001; 18: Suppl 1: $15-21$.

13.- Vergara R. Libro resúmenes XIX Congreso Chileno de Infectología. Santiago, 17-19 noviembre, 2002. pag 61. Resumen PO53.

14.- Heffelfinger J D, Dowell S F, Jorgensen J H, Klugman K P, Mabry L R, Musher D M, Plouffe J R Rakowsky A, Schuchat A, Whitney C G. Management of community-acquired pneumonia in the era of pneumococcal resistance: A report from the Drug-Resistant Streptococcus pneumoniae Therapeutic Working Group. Arch Intern Med 2000; 160: 1399-408. 